\title{
Philosophical aspects of the work of Poincaré
}

\author{
Gaspare Polizzi
}

Published online: 16 May 2013

(c) Centro P.RI.ST.EM, Università Commerciale Luigi Bocconi 2013

\begin{abstract}
The epistemological investigations of Poincaré gave rise to French epistemology. Poincaré's epistemology is also one of the main references for logical empiricism, and the relationship between Poincaré and Enriques allows us to study the matrices of modern epistemology. Even the new concept of space-time proposed by Picasso is closely connected to Poincaré's epistemology. The epistemological and philosophical problems investigated by Poincaré mainly concern deterministic chaos, the concept of space in geometry, the foundations of mathematics and physics and the definition of a general philosophy of science, and also touches on aspects related to morality and materialism. One might say that the philosophy of Poincare is taken to the limit of modernity, to the threshold of twentieth-century epistemology. Poincaré was a careful interpreter of his time, always open to everything new in all sectors of the physics and mathematics, and able to discuss frankly the languages and theories of his fellow philosophers.
\end{abstract}

Keywords Epistemology - Philosophy of science ·

Conventionalism · Non-Euclidean geometry ·

Deterministic chaos $\cdot$ Materialism

\section{Mathematics Subject Classification}

00A30 Philosophy of mathematics

\section{Introduction: the importance of Poincaré for twentieth-century philosophy of science}

At the time of his death, Jules-Henri Poincaré was better known to the wider public for his reflections on philosophy of

G. Polizzi $(\bowtie)$

Via San Zanobi 15, 50129 Florence, Italy

e-mail: gasppo@tin.it science than he was for his extremely significant research in the area of mathematics and physics. In spite of his having published his last scientific paper in March 1912 [25], it was his epistemological investigations, which began with an article of 1887 [22], the year of his first course in mathematical physics at the Sorbonne, that stood out in the public's mind, because the first of his four books dedicated to the philosophy of scienceLa science et l'hypothèse (1902)—had become a bestseller, selling sixteen thousand copies within just a few years. This success was followed by the other three of his epistemological works, all widely distributed and translated into many languages, born together with the first as collections of essays published in a variety of journals for science and philosophy: La valeur de la science (1905, the best known and most important); Science et méthode (1908) and Dernières pensées, published posthumously, shortly after his death (1913).

Poincaré's epistemological investigations not only marked a point of no return in the development in French epistemology, but soon became the object of careful attention throughout Europe, laying the foundations for twentiethcentury epistemology. It suffices to mention the influence that the first two works of epistemology had on the supporters of what would become the principal nucleus for the spread of twentieth-century epistemology, the Vienna Circle, and on the Italian mathematician and philosopher Federigo Enriques.

The physicist Philipp Frank, recalling the early discussions that took place each Thursday starting in 1907 (and lasting until 1912) in an old Vienna café with the economist Otto Neurath and the mathematician Hans Hahn, held that for the young participants in the discussion of philosophy of science, Poincaré-whose La science et l'hypothèse had been translated into German in 1906 and La valeur de la science in 1910 [15, p. 48]—was seen as 'a kind of Kant freed from the remnants of medieval scholasticism and anointed with the oil of modern science' $[7$, p. 8] and his 
'new positivism', to use the expression coined by the philosopher and historian of science Abel Rey in a successful book of 1907, La théorie de physique chez les physiciens contemporaines, led to a constructivism whose its conventional aspects surpassed the thinking of Immanuel Kant and could be conjoined to Ernst Mach's 'principle of economy'. It was just such a conjunction-according to Frank-that gave rise to the epistemological foundation of logical empiricism, born in the Vienna Circle:

Quite early on I became aware that any problem whatsoever of philosophy of science had to consist in the formulation of a theory in which the ideas of Mach and Poincaré were two special aspects of a more general vision. To epitomize these two theories into a single statement, one could say that according to Mach the general scientific principles are abbreviated economic descriptions of observed facts; according to Poincaré they are free creations of the human mind that say nothing about the observed facts. The attempt to integrate the two concepts in a coherent system was the origin of what was later defined logical empiricism [7, p. 12].

The association in Poincaré's work of empiricism and 'criticism on a logical basis' [20, p. 70], recognized by Neurath as well, rendered Poincaré's empiricism an obligatory reference for logical empiricists, who collocated it in the area of the research on 'foundations, aims and methods of empirical science', or on the 'problems of mastering reality through scientific systems, especially systems of hypotheses and axioms' [13, pp. 69 and 87; Eng. trans., p. 304 and 311]. It is interesting to note how the logical empiricists promoted an 'empiricist' view of Poincaré, recalling his teachings in reflections on the foundations of empirical science and on physical geometry, in which Poincaré comes to be seen as the one who 'especially emphasized the link of physical geometry and all other branches of physics: the question concerning the nature of actual space can be answered only in connection with a total system of physics'. ${ }^{\text {' }}$ His vision of geometries as conventional determinations that are unjustified on either an exclusively logical or an empirical level, comes to be seen as an intermediate path between an a priori rationalism of Kantian origin and empiricism, reconcilable with the Machian vision of the theories as 'economical' descriptions compatible with a variety of experimental values. Thus it is no surprise to see the attention paid by a young Albert Einstein, who read and appreciated the German translation of La science et l'hypothèse, even though his relationship to Poincaré was above all competitive and but little explicated, in the context of the formulation of the principle of relativity,

\footnotetext{
1 Ibid., p. 313. The citation continues: 'Einstein then found such a total system, which answered the question in favor of a certain nonEuclidean system'. Poincaré thus comes to be seen as a 'precursor' of Einstein.
}

which Poincaré always viewed — in contrast to Einstein —as experimental evidence. ${ }^{2}$

While the connection to logical empiricism projects Poincaré's thinking into the future history of twentiethcentury epistemology (among other things, also engendering a comparison with Ludwig Wittgenstein in its second phase), ${ }^{3}$ its relation to Enriques allows us to look at the matrices of his epistemology. For his part, Enriques, in his first great work of epistemology, the Problemi della scienza [6], undertakes an intense dialogue with La science et l'hypothèse. ${ }^{4}$ There is no lack of affinity between the two mathematicians, who would meet in person in Paris in 1907, on the occasion of the award of the Prix Bordin to Enriques and Francesco Severi: both brought to maturity their thoughts on epistemology beginning with problems posed by the new geometries; both pondered the possible correspondences between physical reality and mathematics; both grappled with the great turning points in twentieth-century physics (quantum physics and relativistic physics). Just as evident are the divergent outcomes of their epistemological investigations: Poincaré contributed to the birth of conventionalism, privileging the primary importance of the formal and relational dimension of mathematical knowledge and

\footnotetext{
${ }^{2}$ See [21]. For a reference to the value for Einstein of reading $L a$ science et l'hypothèse, see [21, p. 133]; see [21, Ch. 8, pp. 163-176] for the role played by Poincaré in Einstein's formulation of special relativity, which Abraham Pais sums up in the following judgement: 'In 1905 Einstein and Poincaré stated independently and almost simultaneously (within a matter of weeks) the group properties of the Lorentz transformations [so named by Poincare himself] and the addition theorem of velocities. Yet, both Lorentz and Poincaré missed discovering special relativity; they were too deeply steeped in considerations of dynamics. Only Einstein saw the crucial new point: the dynamic aether must be abandoned in favor of a new kinematics based on two new postulates' (p. 21). Pais reconstructed the relationship between Einstein and Poincaré exhaustively, both on a personal level (they met only once, at the first Solvay Congress in Brussels in October 1911), and a scientific level, where competitiveness and reciprocal diffidence prevailed, although mitigated by later admissions, such as Einstein's exhortation to the organizers of an international conference on relativity that took place in Bern in July 1955 to 'honor suitably the merits of Lorentz and Poincaré' (quote on p. 171), although Einstein himself did not attend (he died on 18 April of that year), and private testimony, such as the letter of November 1911 from Poincaré to a colleague (quoted p. 170), as the 'only and definitive judgement', in which Poincaré refers to Einstein as 'one of the most original minds I have known'.

${ }^{3}$ See [9, pp. 61-67 and 94-101]. Gargani underlines the functional link between the Wittgensteinian grammar of mathematical language and mathematical constructivism, asserting that La discussione degli schemi concettuali del Tractatus e la formazione di un nuovo modulo d'analisi hanno la loro matrice nel recepimento da parte del filosofo austriaco di alcune delle tesi centrali dell'intuizionismo di Brouwer e di Weyl' ('The discussion of the conceptual schemes of the Tractatus and the formation of a new module of analysis arose from Wittgenstein's reception of some of theses central to the intuitionism of Brouwer and Weyl') [9, p. 61]; Gargani never mentions Poincaré. ${ }^{4}$ This is discussed in [31].
} 
retracing in the hypotheses the driving force behind scientific development; Enriques was oriented towards an experimental rationalism that maintains a privileges relationship to physical and psychological reality. But both Enriques and Poincaré make evident the need to surpass the traditional formulation of the philosophy of science and of nineteenthcentury gnoseology, tied above all to positivism and criticism, and knowingly engaged in the epistemological concerns, which were shared by a large group of French and Francophile philosopher-scientists. The analogies between these two science-philosophers can thus be explained by means of history. In France at the end of the nineteenth century there was a lively debate over the redefinition of a vision of science that could do without the certainties of positivism and engage with the new horizon opened up by the second scientific revolution, with the profound transformations taking place in mathematics and physics (non-Euclidean geometries, set theory and logicism, thermodynamics, electromagnetism and microphysics). The debate involved philosophers and scientists of various orientations, all engaged in detailed discussions over the new physicalmathematical theories: we need only mention Édouard Le Roy, Abel Rey, mentioned before, Pierre Duhem, Émile Meyerson, Léon Brunschvicg, Louis Couturat, André Lalande, Gaston Milhaud, Louis Weber, Émile and Pierre Boutroux (respectively the brother-in-law and nephew of Poincaré), Émile Picard, Jules Tannery, Paul Langevin, Jean Perrin and Émile Borel. These discussions were particularly intense in the pages of two impassioned journals that also published articles by Poincaré: the Revue de Métaphysique et de Morale in France (beginning with which was founded, in 1901 and with a contribution by Poincaré, the Société Française de Philosophie) and Scientia in Italy (founded in 1907 by Enriques himself, who in his turn would found, in 1906, the Società Filosofica Italiana).

In this symphony of discussions, the only constant that lasted any length appears to be the scant consideration given to questions of formal logic and the ambivalence towards the logician. ${ }^{5}$ Poincaré came to be seen as the father of the critique des sciences (by a mathematician and philosopher of the Bersonian school of the likes of Le Roy), but also as the founder of a 'new positivism' (an expression coined, as we said, by Rey); in any case, modern French epistemology was born with his reflections

\footnotetext{
5 In the concluding chapter of [19] Jan J. A. Mooij draws a final balance that takes this epistemological deficit into account: ... l'on est surpris de voir comment en France c'est précisément le problème de la déduction qui a été abordé à maintes reprises ..., alors qu'en même temps le problème de la logique formelle est minorisé. Intuition et invention sont opposées à la logique; looking back at the whole first half of the twentieth century, he concludes: En dépit des progrès qui ont eu lieu, on a somme toute, l'impression qu'en France la logique formelle n'a toujours pas la place qui lui revient se l'on tient compte des résultats qu'elle permet d'atteindre. See [19], pp. 157 and 158].
}

on science, beginning with the memoire mentioned earlier of 1887 on the fundamental hypotheses of geometry [22].

However, it appears that Poincaré's philosophical work not only infused new lifeblood into the great lines of the international epistemological debate, but also subtly conditioned artistic experience as well. I would like to remark, with a short digression, what was proposed by the historian Arthur I. Miller [18], who looked into the circle frequented by the young Pablo Picasso in Paris in order to identify some of the elements of his formative years that were not part of the aesthetic and pictorial tradition. In the very famous painting Les demoiselles de Avignon (1907), which opens Picasso's cubist period and which is commonly held to have been influenced by a revisitation of Paul Cézanne and the rediscovery of African sculpture and the primitive exotic, partly in the footsteps of Paul Gauguin, Miller has found traces of the debate on the deconstruction of space and time per se. Miller, who has studied visual symbolism in physics, recognizes a common predisposition of scientists and artists towards the search for a visual representation of the world. In the effervescent intellectual climate of Paris during the Belle Epoque, Picasso seems to have, thanks to his friend the mathematician Maurice Princet, come into contact with Poincaré's epistemological work, and in particular to the non-Euclidean approach to geometry and its speculations on simultaneity. This occurred precisely during the years 1906-1907, when Picasso 'discovered' cubism, even though with regard to this Picasso himself recalled the influences of Guillaume Apollinaire, Henri Bergson, Mach and Cézanne, and the attraction to $\mathrm{X}$-rays and cinema, without over mentioning either Poincaré or his young mathematician friend. For Miller, the new vision of space-time offered by Les Demoiselles de Avignon appears to involve an aesthetic of the $n$-dimensional continuum, very closely connected to Poincarè's epistemology, not only because of Poincaré's assertion about the constructive and relational character of spatial knowledge, which makes it possible, with the auxiliary of different geometries, not only to know objects but to also know their relationships to each other, but also because his theses about creativity, both scientific and artistic, were interpreted as the capacity to unite pre-existing elements into new combinations that appear beautiful, both in an aesthetic sense and in the sense of beauty as perceived by mathematics, that is, as harmony and elegance. ${ }^{6}$ Thanks to Princet, Picasso is supposed to have taken into consideration the new concept of space-time visualization, modeled on nonEuclidean geometries; it may have been thanks as well to the representations on the two-dimensional plane of hypercubes and other four-dimensional complex polyhedra that appeared in the Traité élémentaire de géométrie à quatre dimensions (1902) by the mathematician Esprit Jouffret, which popularised Poincaré's geometrical theories.

$\overline{{ }^{6}}$ See [27], Ch. III, 'Mathematical Creation', pp. 383-394]. 
Returning from this brief excursus to Poincaré's philosophical thoughts, it appears opportune to briefly recall his concepts in epistemology and philosophy of science, as well as his more general philosophical ideas, always closely connected to his scientific, and especially his mathematical work, and aimed at a prevailing need to clarify the theories and the language of mathematics and sciences.

While, as has been written, les principales thèses philosophiques de Poincaré apparaissent pour la première fois dans ses préfaces, that is, while the prefaces to his scientific works form a sufficient basis for reconstructing Poincaré's epistemology, it has however been ascertained that the weight carried by his reflections in the epistemological debate of his day and later, can be referred to the four volumes mentioned above, which moreover reprennent de manière plus fouillée ceux déjà annoncés dans les préfaces des cours à la Sorbonne [3, pp. 221-222].

The epistemological and philosophical problems raised by Poincaré primarily regard 'deterministic chaos', the geometries and the concept of space, and the foundations of mathematics and physical theories, and give form to a general philosophy of science, touching as well on aspects relative to morals and materialism. I will provide a few lines of reading, without any pretense of being exhaustive, not entering here into the reflections on the foundations of mathematics, investigated by Gabriele Lolli. ${ }^{7}$

\section{Reflections on deterministic chaos}

In Science et méthode, writing about the role of chance in physics, Poincaré offered a metaphor for the correspondence between physics and history: just as in random physical phenomena a small cause can produce large effects, so too in history a chance event can produce large consequences, and 'the greatest bit of chance is the birth of a great man' are born who change the course of history [27, p. 410]. This comparison clearly shows the extent to which Poincaré's reflections on chaos had already produced an outcome that was generally philosophical, oriented towards a conception of history that was not in keeping with deterministic and progressive historicism.

The chapter on chaos in Science et méthode [24] takes us into the heart of that complex vision of nature that Poincare had studied in the course of research that would come to be categorized as 'deterministic chaos' which he had already evoked earlier in his first book of popular science, La Science et l'Hypothèse, where he wrote: 'We are therefore led to adopt the same course as if a simple law were, other things being equal, more probable than a complex law. A century ago it was frankly confessed and

${ }^{7}$ For a general overview, [34] remains helpful. proclaimed abroad that Nature loves simplicity; but Nature has proved the contrary since then on more than one occasion' [24, p. 120].

Let us look briefly at the innovative aspects of the theory of 'deterministic chaos'. In Science et méthode Poincaré offers three clear examples of instable equilibrium: the spinning of a top, atmospheric turbulence, and the distribution of small planets within the zodiac. ${ }^{8}$ 8 The entire passage is worth quoting for its effectiveness: 'We will select
unstable equilibrium as our first example. If a cone is balanced on its point,
we know very well that it will fall, but we d not know to which side; it seems
that chance alone will decide. If the cone were perfectly symmetrical, if its
axis were perfectly vertical, if it were subject to no other force but gravity, it
would not fall at all. But the slightest defect of symmetry will make it lean
slightly to one side or other, and as soon as it leans, be it ever so little, it will
fall altogether to that side. Even if the symmetry is perfect, a very slight
trepidation, or a breath of air, may make it incline a few seconds of arc, and
that will be enough to determine its fall and even the direction of its fall,
which will be that of the original inclination.

'A very small cause which escapes our notice determines a considerable effect that we cannot fail to see, and then we say that that effect is due to chance. If we knew exactly the laws of nature and the situation of the universe at the initial moment, we could predict exactly the situation of that same universe at a succeeding moment. But, even if it were the case that natural laws had no longer any secret for us, we could still only know the initial situation approximately. If that enabled us to predict the succeeding situation with the same approximation, that is all we require, and we should say that the phenomenon had been predicted, that it is governed by laws. But it is not always so; it may happen that small difference in the initial conditions produce very great ones in the final phenomena. A small error in the former will produce an enormous error in the latter. Prediction becomes impossible, and we have the fortuitous phenomenon.

'Our second example will be very like our first, and we will borrow it from meteorology. Why have meteorologists such difficulty in predicting the weather with any certainty? Why is it that showers and even storms seem to come by chance, so that many people think it quite natural to pray for rain or fine weather, though the would consider it ridiculous to ask for an eclipse by prayer? We see that great disturbances are generally produced in regions where the atmosphere is in unstable equilibrium. The meteorologists see very well that the equilibrium is unstable, that a cyclone will be formed somewhere, but exactly where they are not in a position to say; a tenth of a degree more or less at any given point, and the cyclone will burst here and not there, and extend its ravages over districts it would otherwise have spared. If they had been aware of this tenth of a degree, they could have known it beforehand, but the observations were neither sufficiently comprehensive nor sufficiently precise, and that is the reason why it all seems due to the intervention of chance. Here, again, we find the same contrast between a very trifling cause that is inappreciable to the observer, and considerable effects, that are sometimes terrible disasters.

'Let us pass to another example, the distribution of the minor planets on the Zodiac. Their initial longitudes may have had some definite order, but their mean motions were different and they have been revolving for so long that we may say that practically they are distributed by chance throughout the Zodiac. Very small initial differences in their distances from the sun, or, what amounts to the same thing, in their mean motions, have resulted in enormous differences in their actual longitudes. A difference of a thousandth part of a second in the mean daily motion will have the effect of a second in 3 years, a degree in ten thousand years, a whole circumference in three or four millions of years, and what is that beside the time that has elapsed since the minor planets became detached from Laplace's nebula? Here, again, we have a small cause and a great effect, or better, small differences in the cause and great differences in the effect'; see [27, pp. 397-398]. 
The second example, drawn from meteorology, looks extremely modern: the meteorologist Edward Lorentz would define this kind of chaotic phenomena as 'the butterfly effect'. More generally, the identification of non-linear systems, far from a state of equilibrium, constitutes the new line of reference along which the applications to astronomy of Poincarè's mathematical investigations would develop, giving rise to the mathematics of 'deterministic chaos'. The opportunity for this arose from research in astronomy and the attempt to validate the cosmic determinism derived from Newtonian theory and given form in the synthesis of Laplace, leading to the proposal, in 1889, of a solution to the well-known three-body problem, which consisted in the definition of the gravitational interactions relative to three (or more) celestial bodies by means of the calculus of their reciprocal perturbations. The effectiveness of the hypotheses proposed by Poincaré lies primarily in the power of the mathematical instruments he used, aided by the discovery of automorphic functions, that is, functions of complex variables that are invariant under the action of some transformation group. The transformation group associated with a Fuchsian function (a particular type of automorphic function) is composed of polygons whose sides describe arcs of circles. The surface covers what is known in algebraic topology as a 'simply connected' region of the plane, and the transformations permitted by this kind of surface composed of curvilinear polygons form a group that describes the nonEuclidean geometry of János Bolyai and Nikolai Ivanovich Lobachevsky. The use of a non-Euclidean geometry to solve a problem of mathematical analysis shows how, for Poincaré, non-Euclidean geometries became instruments for generalizing analysis: in the context of a geometric conception of analysis, analytical problems are illuminated by geometric intuitions that make use of different metrics. In this way Poincaré contributed to the effective insertion of non-Euclidean geometries in an analytical vision of the physical world, expressed mechanistically in differential equations. Poincaré's attempt at solving the three-body problem reawakened doubts regarding the stability of the Newtonian system. The study of the continual evolution of a dynamic system was transformed into a geometric problem: the analysis of a discontinuous series of points in the plane. Thus there arose, for the first time, the need to calculate with precision the sensitivity to initial conditions of a process in a dynamic system, in function of their importance: the theory of dynamic systems would lead to the birth of the 'geometry' of chaos. Today a dynamic system is considered to be 'chaotic' when the imprecision with which is known the $n$th term of the series tends to infinity, when $n$ tends to infinity. It is impossible to predict the behaviour of such a system, since the further away the desired point of prediction of the evolution of the system itself is, the higher the degree of precision with which its initial state is known must be. Chaotic dynamic systems are deterministic, but not predictable. It is possible to classify their asymptotic states (associated with what today are called 'strange attractors'); it is also possible to attribute probabilities to them. ${ }^{9}$ It was disconcerting for a 'classical' mathematical physicists, as Poincaré was, to recognize that chaotic phenomena rigorously describing the emergence of a series of necessary concatenations beginning with a chance occurrence, could emerge from a typically deterministic problem of Newtonian mechanics. Poincarés extraordinary journey into the complexity of the interactions of planetary orbits led to the discovery of figures of equilibrium and bifurcation, later studied in the elementary version of catastrophe theory, developed René Thom. The new geometric figures investigated by Poincaré, such as the pseudosphere and the torus, today form the basis of contemporary geometry, much as the cube and cylinder constituted the basis for classical geometry.

But the most significant epistemological outcome of this research lies in the admission of the chaoticness intrinsic in the behaviour of all systems, such as that of the three celestial bodies, which are subject to non-linear forces: except for a discrete set of simple periodic solutions, in general there is no finitary solution that can be effectively calculated beginning with assigned initial conditions. As Claudio Bartocci remarked, 'This discreticizing of dynamics is a theoretical acquisition of primary importance, which has only recently_almost a hundred years after Poincaré's discovery-found applications in many areas of science, from biology, to physics, to engineering' $[1, \mathrm{p} . \mathrm{XXXI}]$. The qualitative path of the system's trajectories, in proximity to a simple periodic trajectory, shows a continual transition of regular and predictable motion of the periodic trajectory of reference leading to trajectories that are irregular and chaotic: in the end, minimal differences in initial conditions can lead to very large differences capable of compromising the very possibility of predicting the system and rendering its behaviour random. The phenomena can be described by the differential equations of classical dynamics, used by Pierre-Simon Laplace and inspired by Isaac Newton, but the mathematical 'determination' of a phenomena does not guarantee that it can be predicted (the dynamics of such phenomena thus appear to be 'chaotic' because they are not predictable). Topological studies of 'deterministic chaos' define mathematical magnitudes that identify the type of disorder being studied, beginning with the assertion-stated for the first time by Poincaré-that the various types of disorder cannot be predicted, but can be described and classified. If we want to

\footnotetext{
${ }^{9}$ One example of a chaotic dynamic system is the motion of a die, which is unpredictable but whose positions at infinity are the six faces of the die itself, the six 'strange attractors' of the system, to each of which can be attributed a probability of $1 / 6$.
} 
identify a broader cultural significance of the corner turned by Poincare we might compare the image of the world he proposed with that of Laplace. In the span of a century we go from a simple universe to one of contingencies and unexpected passages. In contrast to Laplace's cosmic determinism Poincaré proposed topological surfaces and unpredictable phenomena. It is astonishing that this 'approximate mathematics' foreseen by Poincaré, but also by Jacques Hadamard and Pierre Duhem, would have to wait 70 years to attract the attention of physicists and mathematicians once again. ${ }^{10}$

\section{Reflections on geometries and the concept of space, between physics and mathematics}

The reflections on 'deterministic chaos', so exploited by contemporary epistemology, did not have any particular echo in Poincaré's day. Instead, the most relevant aspect of Poincaré's epistemology was thought to be the investigations of geometries, and certainly the best known trait of his epistemology of geometry resides in the conception of geometric spaces that grew out of his studies of automorphic functions, in which he introduced two concepts that are key to modern topology - the concept of homology, and that of fundamental group of a variety (or first homotopy group) - and proved the correspondence between the axioms of any given geometry and the algebraic transformation groups. His conception of geometric spaces rested on the hypothesis of a regulated translatability of the spatial parameters of Euclidean geometry into those of nonEuclidean geometry. From this followed, on the epistemological level, that geometry studied transformation groups and the existence of a (Euclidean) group is not compatible with that of another (Lobachevsky) group. In function of the study of physical space it is then necessary to choose a particular transformation group to be related to the physical phenomena; for Poincare the simplicity of the Euclidean group and the fact that the movements of rigid bodies are subject to relations that refer back to the operations of that group, tend to lead to its being chosen.

In an essay of 1891 Poincaré draws his own epistemological conclusions from the studies of non-Euclidean geometries, introducing the theory of the conventional nature of geometric axioms: 'Geometric axioms are therefore neither synthetic a priori intuitions nor experimental facts. They are conventions. Our choice among all possible conventions is guided by experimental facts, but it remains free, and is limited only by the necessity of avoiding every contradiction...' [24, p. 65]. The use of the concept of 'convention', which is found here for the first

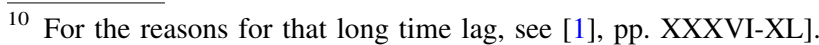

time (in place of that of 'hypothesis'), allows Poincaré to formulate a genuinely original solution to the question of the nature of geometric axioms, unconnected to both the Kantian view of a priori, and the strictly empirical. $\mathrm{He}$ debates the meaning of the term, which comes to be used together with the expression définition déguisée, taking it back, for example, to that of choix décisoire (André Lalande ${ }^{11}$ ), but Poincaré-as Jan J. A. Mooij has remarked ${ }^{12}$ - did not intend to express the sense of accord or understanding, but rather the notion of habit. In his way the convention is connected with the conditions of the metric, in a direction much appreciated by Einstein, who was studying metric systems in function of non-Euclidean spaces. ${ }^{13}$ Einstein's interest in Poincaré's geometric philosophy is a further indication of the correspondences mentioned earlier. It should be added that the conventionality of the laws of nature was dealt with in an important essay of 1935, 'Are Natural Laws Conventions?' by Moritz Schlick [35], beginning precisely with the conception of Poincaré. Schlick, however, underlined the interaction between linguistic conventionalism and factual relations in contrast to extreme conventionalism, and making use of the distinction between pure geometry and applied geometry and of the empiricist and linguistic

\footnotetext{
11 See [17, pp. 187-188]. Lalande concludes the entry with the following remark: 'Il serait donc bien préférable de ne pas retenir pour exprimer cette idée le mot convention, et de parler plutôt de décision volontaire ou de choix décisoire'.

12 See [19], pp. 23-24]. An accurate analysis of Poincaré's conventionalism can be found in [12], which cites the texts of Bertrand Riemann on space as a metrically amorphous continuous variable; see also [10], which reconstructs the entire 'conventionalist' epistemology of Poincaré, identifying the matrices in the concepts of invariance (derived from the research works on automorphous functions beginning with the work of Sophus Lie) and of relativity.

13 With regards to this Mooij cites an observation of Paul Arthur Schilpp: 'La question des conditions dans lesquelles l'on mesure est fondamentale pour la théorie de la relativité et la recherche dans ce domaine a abouti à la conclusion, qu'outre la géométrie euclidienne d'autres géométries peuvent être données comme fondement à la physique. C'est ce qui explique le grand enthousiasme d'Einstein pour la philosophie géométrique de Poincaré' [35, p. 24]. Louis Rougier has offered four possible definitions for conventionconvention of writing, nominal convention, interpretational convention, instrumental convention-and maintains that in Poincaré Euclid's postulate is treated either as a nominal convention or an instrumental convention [33, pp. 122-123]. But Mooij maintains that Rougier's distinction between pure geometry and applied geometry is not valid, and that Poincare always considered the acceptance of Euclidean geometry within a practical system of measurement: ' $\mathrm{Sa}$ notion de 'convention' n'a pas trait à une théorie axiomatique abstraite. Elle caractérise les axiomes par rapport à la réalité de l'expérience qui a servi de motif et en tant qu'ils continuent à y être engagés' [35, p. 25]. Nor, adds Mooij, can the expression définition déguisée be considered a synonym for définition implicite, as Rougier claims, citing axiomatics: the axioms are définitions déguisées in as much as they determine a practical system of measurement. The decision that concerns applied geometry is a question of convention.
} 
interpretation of Poincaré's conventionalism proposed by Rougier. After maintaining, following in the footsteps of Poincaré, that 'geometry is the grammar of the language in which we describe the spatial relationships of physics', Schlick concludes against a conventionalistic view: 'All these "grammatical" rules and these alone together determine the meaning of the propositions of science. For the meaning of a sentence is indicated if and only if it is precisely stated how the sentence is to be used: and that is precisely what these rules do. They are the only conventions, not the natural laws' [35 pp. 443-444].

In Poincarè, the scientific root of commodisme (this is the term he used to designate his conventionalism) makes use of a parallel reading of representative space and geometric space: the former (in its threefold form, visual, tactile and motor) can be reduced to the second only by means of a translation that is partial and necessarily approximative, which reveals the reciprocal correction between involuntary external mutations and voluntary bodily mutations. Further, according to Poincaré there exists an idea already conceived in the mind - the general concept of group—starting with which the geometric parameters are elaborated:

The concept of the ideal bodies [ideal solids] is entirely mental, and the experiment is but the opportunity which enables us to reach the idea. The object of geometry is the study of a particular 'group', but the general concept of group pre-exists in our minds, at least potentially. It is imposed on us not as a form of our sensitiveness, but as a form of our understanding... ${ }^{14}$

In the end, the various possible geometries are the study of the movements of bodies in space whose formal relationships established by the transformation groups remain unaltered; the postulates of the various geometries are theoretical hypotheses and therefore differ only in the different ways of defining the distances between the bodies. In other words, no geometry is more true or more false than another: the only experimental datum relative to the construction of the geometrical spaces is the existence of the rigid bodies. If there were no rigid bodies, there would be no geometries. Thus, our choice when confronted with diverse geometric spaces that can be constructed in a conventional manner is related to convenience (hence commodisme, or 'commodiousness'), simplicity and logical coherence; the decision, therefore, of whether or not a given geometry is valid or not is based on these criteria. In this case, Poincaré, already in the article of 1887-and this is a position that would remain fixed over the course of his thinking — speaks of the criterion of convenience, that is, of the one that will lead him to support Euclidean geometry: it may not be more true than the others, but it is more convenient and should thus be maintained as such.

\footnotetext{
14 [24, p. 79]. (This chapter reprises the earlier essay ' $L$ 'espace et la géométrie' [23]).
}

This is a position that reflects the richness of the debate in France over non-Euclidean geometries, which, beginning in 1866, that is, with the spread in France of the knowledge of these new geometries, would lead to a lively confrontation between philosophers and scientists: the philosophers were reluctant to accept them, because they were considered to be imaginary suppositions, pure mathematical games, with no possibility of augmenting knowledge about physical space. In France the debate was partly hegemonized by the philosophers; it suffices to recall Charles Renouvier, a philosopher whose orientation was Kantian, who maintained that the presuppositions of non-Euclidean geometries were absurd. ${ }^{15}$ Poincaré's interventions were always aimed at defending of the value of truth of non-Euclidean geometries and in denying that geometry was an experimental science.

In spite of the criticisms of an empiricist nature of Enriques and Hans Reichenbach, ${ }^{16}$ who saw Poincaré's

\footnotetext{
15 The development of the French debate over non-Euclidean geometries, in which Poincaré participated directly, had two phases. The first phase (from 1866 to 1893), successive to the spread in France of Lobachevsky's geometry (thanks to Jule Hoüel and expounded on in the works of Renouvier, Couturat, Paul Tannery, Auguste Calinon and George Lechalas), centered on discussions of the concept of geometric space, with hypotheses of various kinds of space in abstract, and a distinction made between geometric space and physical and contingent space. In the second phase (1893-1912), the discussion became international, coming to involve Bertrand Russell, who was inclined towards a vision in which metric geometry was empirical, thus making it possible to establish the Euclidean character of physical space empirically. Poincaré's part in the debate is collocated in that context, as he maintained the distinction between physical space, continuous and infinite, and geometric space, and put together a 'constructive' theory of geometry tied to the concept of transformation groups and the relativity of representative space, psychological image determined by the human experience of solid bodies (referring to concepts developed by Helmholtz, and hypothesising that experience tends to lead to Euclidean geometry, which is more convenient than others. In the end, Poincare wanted to show that geometry is a branch of pure mathematics and acts as a bridge between mathematics and physics.

${ }^{16}$ Reichenbach viewed conventionalism as an idealistic derivative of Kantian criticism which took no account of the constitutive character of the concept of object, understood in its physical reality. In his final work we once again find criticism of conventionalism combined with that of neo-Kantian subjectivism: 'If every geometry can be applied to the physical world, it seems as though geometry does not express a property of the physical world and is merely a subjective addition by the human observer, who in this way establishes an order among the objects of his perception. Neo-Kantians have used this argument in defense of their philosophy, and it was used in a philosophical conception called 'conventionalism', introduced by the French mathematician Henri Poincaré, according to whom geometry is a matter of convention and there is no meaning in a statement which purports to describe the geometry of the physical world'. However, Reichenbach responds to this, 'There is no synthetic a priori of geometry: either geometry is a priori, and then it is mathematical geometry and analytic-or geometry is synthetic, and then it is physical geometry and empirical. The evolution of geometry culminates in the disintegration of the synthetic a priori.' See [32, pp. 133 and 140].
} 
conventionalism as a prolongation of Kantism, and the opposing observations of the mathematician Hans Freudenthal on the lack of an axiomatic framework of the geometric problem and the prevalence of a empiricist vision of space, derived by Hermann Ludwig Ferdinand von Helmholtz, ${ }^{17}$ the assertion of Mooij on the legitimacy of conventionalism is shared by many:

Et en général, il est dangereux de manier l'empirisme et le Kantisme comme pierre de touche. Le fait que la théorie de Poincaré présuppose l'activité créative de l'esprit humain n'est pas plus suffisant pour le qualifier de Kantiste (raté ou déguisé) que le fait qu'il accepte l'expérience est suffisant pour le qualifier d'empiriste (raté). La position intermédiaire qu'occupe le conventionnalisme est en soi légitime [19, p. 28].

But if it is necessary to be inclined towards one or the other horn of dilemma, it should be said that Poincare proposed a new conception of the a priori, by means of changing the orientation of Kantian theory from transcendental aesthetics to transcendental analysis. The a priori is understood as an implicit precondition in experimental revelation. In consequence, the criticism of geometric empiricism is clear: spatial experience regards the movements of solid bodies in space, but does not make it possible to know the relationships that exist between the bodies within a given space. If the laws governing the form of the real bodies derive from the mathematical notion of equality (with Helmholz), there is however a logical inconsistency in non-Euclidean geometric varieties, justifying the conventional nature of the geometric postulates. In a certain sense, Poincaré's conventionalism is coherent with certain Kantian presuppositions: Poincaré proposes his conception of the a priori, according to which the various possible geometries arise from the transformation groups which are virtually existing and innate in our mind. The choice is in part conventional, that is, it is given by the criteria of convenience, but there are universal invariants. In this, Poincaré's position can be considered as a kind of weakened Kantism.

The concept of 'convention', formulated in the epistemology of geometry, thus makes it possible to respond in a new way to the classical gnoseological questions regarding the foundations of geometry, the nature of geometric reasoning, and the relationship between geometry and the outside world.

\footnotetext{
17 According to Freudenthal, Poincaré would use the axioms in an imprecise way, remaining anchored to an empiricist vision of space, reprised from Helmholtz and ignoring the axiomatic tradition expressed by Moritz Pasch, Giuseppe Peano and Mario Pieri. The question of the 'convenience' can be judged only by beginning from a system of axioms, not in reference to an isolated axiom, as Poincaré suggests. See [8]; see also [19, pp. 28-29].
}

\section{From the philosophy of physics to the philosophy of science}

Poincaré's field of philosophical investigation transcends the specific area of the epistemology of mathematics and physics and leads to a more general philosophy of science. Indeed, it can be said that his epistemology expands towards a 'scientific philosophy', although one whose formulation was not coherent and preordained, but rather scattered throughout various articles and essays. Although Poincare maintained that the scientist could occupy himself with only methodology and foundational problems of his own particular science and had to step back from a vision of science that was all-embracing, philosophical and metaphysical, and although his nephew Pierre Boutroux wrote that his uncle was an autodidact in philosophy and was especially mistrustful of metaphysical systems [2], all four of Poincaré's epistemological works also contain a philosophy of science in a broader sense.

The concepts of group and invariant ${ }^{18}$ (which unite geometry, algebra and analysis ${ }^{19}$ ), and of complete induction (tied to arithmetic) make it possible to identify a science in which convention and construction assume preeminent roles, without diminishing the value of truth of scientific theories.

The most sensitive point of such a 'compromise' lies in the conception of a 'physics of principles'. From his earliest studies of mathematical physics (on the optic theory of Augustin-Jean Fresnel and on the theory of potential), Poincaré provides an indication of the hypothetical nature of mathematical physics. The exploitation of hypothesis in physics, as a 'convenient' means for formulating problems by means of differential equations, makes it possible to distinguish in all theories, beginning with the studies of the kinetic theory of gases, the physical hypotheses from the general principles that the theory is based upon. To this hypothetical dimension is added the divergence of the 'national styles' in physics, recognisable in James Clerk Maxwell's presentation of the theories of electromagnetism, which make scientific communication difficult. ${ }^{20}$ The principles are understood as a small number of fertile generalisations of the hypotheses assumed from the theory, useful for understanding the mass of experimental results; they do not derive from empirical data, but are subject to mathematical proof and in consequence must be rigorous,

\footnotetext{
18 'Among words that have had the most fortunate influence [in mathematics] I would select 'group' and 'invariant' [27, p. 375].

19 'It looks as if geometry could contain nothing which is not already included in algebra or analysis, thus, geometric facts are only algebraic or analytic facts expressed in another language' [27, p. 380]. 20 'The Latins seek in general to put their thought in mathematical form; the English prefer to express it by a material representation', see Poincaré's 'Author's Preface', p. 5 in The Foundations of Science.
} 
while the experimental data can have a degree of approximation. ${ }^{21}$ Poincare initially deduced from this that the principles of mechanics cannot be debated, because they are mathematically tested. The 'physics of principles' abandons the mechanistic project of an integral knowledge of the structure of the universe, limiting itself to acting as a guide to some generalisations of experience subjected to continuous verifications, and thus in possession of 'an eminent degree of certainty'. The development of molecular physics, enriched by experimental data and statistical laws, seemed to threaten the 'physics of principles', and Poincaré recognised the difference, which would be present in Einstein's thinking as well, between constructive theories and the theories of principles. ${ }^{22}$ The later research of Poincaré himself on quantum theory, electromagnetism and the dynamics of the electron, of which he provided a constructive interpretation, would blur the differences and weaken the conception of the 'physics of principles'.

To give an account of the effectiveness of Poincaré's intuition regarding physics, we cannot forego mentioning his criticism of the objective value of the concept of simultaneity, which appeared as early as 1898 in an article entitled 'La mesure du temps', later included in La valeur de la science-where he observed, 'We have not a direct intuition of the equality of two intervals of time' [30, p. 224]. This assertion, and that of the 1904 lecture entitled 'L'état actuel et l'avenir de la physique mathématique', also included in chapters VII, VIII and IX di La valeur de la science ('Perhaps to we shall have to construct an entirely new mechanics that we only succeed in catching a glimpse of, where, inertia increasing with the velocity, the velocity of light would become an impassible limit' [30, p. 319]) show how Poincaré's project for research, which came together in the two important memoires 'Sur la dynamique de l'électron' of 1905, touched on the same problems addressed by Einstein in the special theory of relativity. Moreover, on the question of the measurability of time Poincaré became involved in a discussion with Bergson and his disciple Le Roy, who attempted,

\footnotetext{
${ }^{21}$ The six principles considered fundamental by Poincare are: the principle of conservation of energy, the principle of the degradation of energy, the principle of the equality of action and reaction, the principle of Galilean relativity, the principle of conservation of mass, and the principle of least action. See [30, Ital. trans, pp, 126-128].

22 The 'constructive theories' are based on principles or axioms from which the entire theory is derived in a deductive fashion, interpreting complex phenomena in terms of statistical laws (this is the case of the kinetic theory of gases). The 'theories of principles' make use of the analytical method and are based on principles proved experimentally, such as the second law of thermodynamics, which function as heuristic principles. Einstein counted the theory of special relativity as one of the theories of principles, while Poincaré viewed it as a constructive theory, one that presumed to describe the general state of the universe. See [5, pp. 72-79].
}

unsuccessfully (as I shall mention below) to enlist him in the spiritualistic nouvelle philosophie.

In 1954, during the celebrations for the hundredth anniversary of Poincaré's birth, the experimental physicist Maurice De Broglie gave an inaugural address entitled 'Henri Poincaré et la Philosophie' [4], remarking the profound difference between theoretical physics and mathematical physics, in which prevails the mathematical and critical examination of theoretical physics in order to render it rigorous and place it in its proper context within the mathematical sciences. Poincaré was a mathematical physicist and from his professional skills arose his preeminent interest in the notions of time and space, expressed in La valeur de la science. However, it must be added that his comparative commitment and his evolutive and pluralistic conception of physical theories led him away from that static research of mathematical rigour present in many French mathematical physicists and noticed by De Broglie. Mathematical physics must render the degree of predictability of physics increasingly more efficient, even though it is limited to recompiling the catalogue. His attention led him to an original epistemology of geometry, but in any case, according to De Broglie, the perspective of a 'physics of principles' turned out to be inadequate, watered down as it was in Science et méthode, and even more so in Dernières pensées, where the experimental character of mechanics is addressed, the primacy of experience is underlined, and the conception of the contingency of the evolution of natural laws proposed by his brother-in-law Émile Boutroux (Fig. 1) is streamlined. With regard to this Poincaré wrote: "What is the use of wondering whether in the world of intrinsic things the laws can vary with time whereas in a similar world the word "time" is perhaps meaningless? What this world consists of, we cannot say nor conjecture, we can only conjecture what it seems, or might seem to be to minds not too different from ours' [28, p. 13].

\section{Towards a philosophy of science}

The criticisms of the weakness of 'physics of principles' aside, Poincarè's philosophy of science expresses a strong link with the tradition of modern science, appears attentive to the historic evolution of the theories, while continuing to give central importance to the principle of the fundamental unity of science.

The book that best testifies to that 'nineteenth-century' faith in science is La valeur de la science, a collection of essays published between 1897 and 1904 which would soon become one of the points of reference for the philosophical and epistemological community in Europe, especially the German speakers (think of logical empiricism). 
The book's third part, 'The Objective Value of Science', proposes a general philosophy of science oriented towards an attitude of research and of openness to understanding the world, in which, for Poincaré, lies the inestimable value of science. This part is composed of two chapters, $\mathrm{X}$ and $\mathrm{XI}$, whose titles are unequivocal: 'Is Science Artificial?' and 'Science and Reality'. Poincaré feels the need to defend himself from those who he believes intentionally misconstrue his first work of epistemology, La science et l'hypothèse, especially the spiritualist philosophers, and Bergson and Le Roy in particular, who read Poincaré's conventionalism as an example of the critique des sciences and of the spread of nominalism, and in the final analysis as a sign of the failure of scientific knowledge to obtain to the truth of the real work. Poincaré responds by maintaining that scientists possess a linguistic creativity, that they construct languages that are mathematically coherent and convenient, but that there always exist universal invariants of the sort that make theoretical languages translatable, both from one scientific theory to another, and from scientific facts to the so-called 'crude facts'. It is always possible to translate scientific language into the objective relations that regulate crude facts: and thus there exists an objectivity of science, even though not founded on knowledge of the single 'crude fact', but of the system of relations, substantially mathematical, that govern experimental data. The unsuppressible value of science, that which distinguishes it from other languages that are also creative, consists in its capacity to arrive at a system of objective knowledge about relationships between phenomena. Science is valid for its own sake because it alone has the capacity to think about the world in a creative mathematical language:

'It is only through science and art that civilisation is of value. Some have wondered at the formula: science for its own sake; and yet it is as good as life for its own sake, if life is only misery; and even as happiness for its own sake, if we do not believe that all pleasures are of the same quality, if we do not wish to admit that the goal of civilisation is to furnish alcohol to people who love to drink. ... All that is not thought is pure nothingness, since we can think only thought and all the words we use to speak of things can express only thoughts, to say there is something other than thought, is therefore an affirmation which can have no meaning. And yet-strange contradiction for those who believe in time-geological history shows us that life is only a short episode between two eternities of death, and that, even in this episode, conscious thought has lasted and will last only a moment. Thought is only a gleam in the midst of a long night. But it is this gleam which is everything' [30, Eng. trans., p. 355].

It was partly due to these statements about the 'value of science' that the thinker and poet Paul Valéry saw in Poincaré (as many pages of the Cahiers testify) an exemplary model of the modern scientist. One example will suffice. In
Fig. 1 Family reunion in Remenoncourt in 1907. Shown in the photograph, in addition to Poincare (on the far right) are his sister Aline and her husband, Émile Boutroux. Reproduced by generous permission of the LHSP_Archives HenriPoincaré. UMR 7117 CNRS/ Université de Lorraine

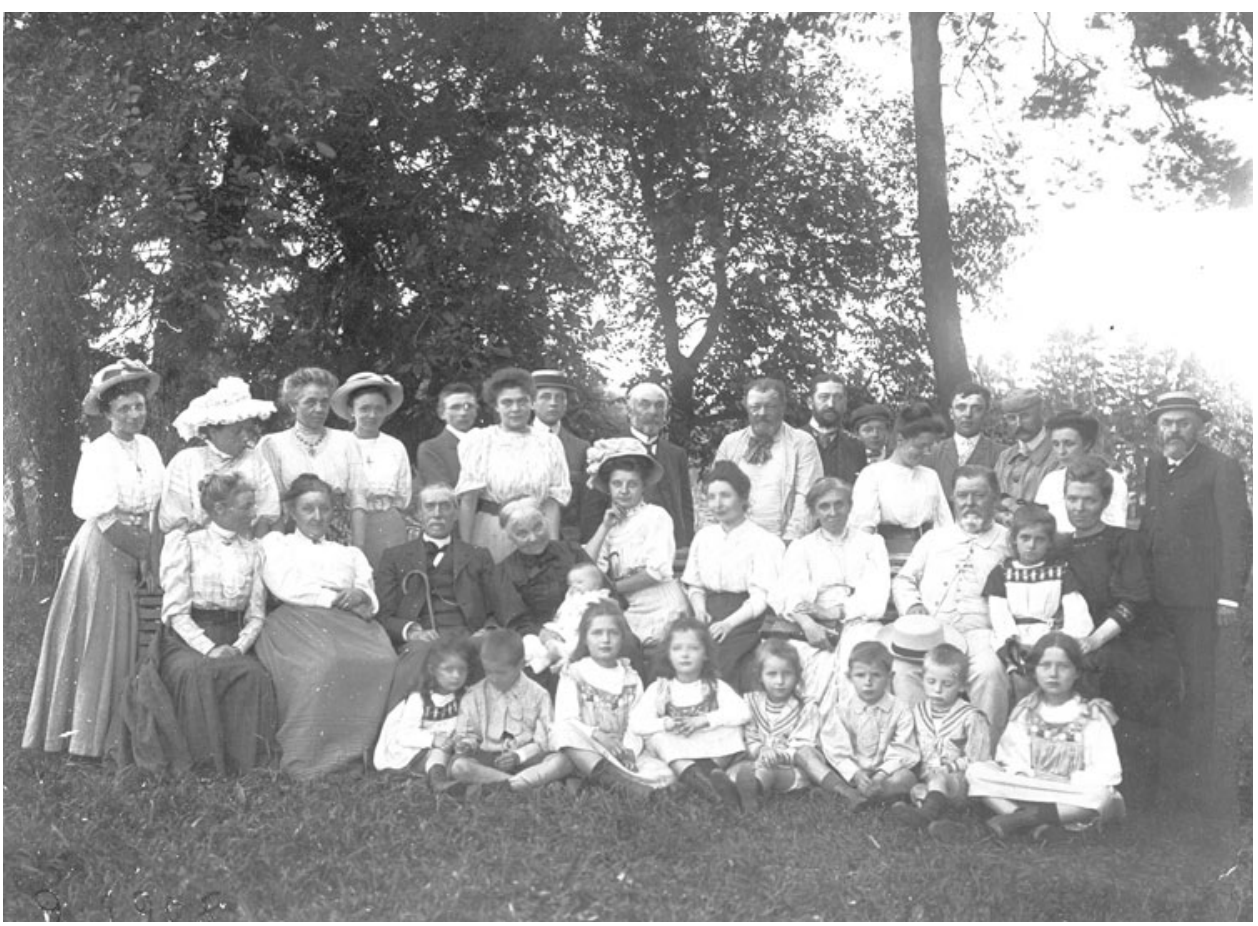


the Premières notes et esquisses de plans [36, p. 279], which are the point of departure for a long project of investigation into the creative method of Leonardo da Vinci, a first synthesis of which was published as Introduction à la Méthode de Léonard de Vinci (1895); Valéry proposes the triad Poincaré/Laplace/Descartes, to express the two alternate visions of natural order-mechanistic with Descartes and Laplace, and complex with Poincaréand to show in Poincaré's vision the directrix that exemplifies twentieth-century science. More than to the Poincaré of geometric commodisme, Valéry is inclined towards the Poincaré who promotes a topological and 'complex' vision of the world and a theory of scientific creativity (so appreciated, as we have seen, in artistic and literary circles), for his formal capacity to link the finite to the infinite, in the sign of a homogénéité du pouvoir mathématique au pouvoir de l'esprit. ${ }^{23}$ The gradation of complexity promoted by Poincare is the measure of the game of circumstances that Valéry sees as an essential condition for the invention of not only geometric figures, but of the imaginary objects of literature. It should be added that the exploitation recommended by Valéry of Poincaré's thoughts on creativity are also based on direct testimony, related to the mens creativa of Poincaré, the mathematical genius who had no students, such as that, for example, given by his nephew Pierre Boutroux, who wrote:

Tout le travail de découverte se faisait mentalement chez mon oncle, sans qu'il eût besoin, le plus souvent, de contrôler ses calculs par écrit ou de fixer ses démonstrations sur le papier. Il attendrait que la vérité fondît sur lui comme le tonnerre, et il comptait sur son excellente mémoire pour la conserver. ${ }^{24}$

With in the overall framework of the philosophy of science, Poincaré also dedicated particular attention to the question of

\footnotetext{
23 Jeannine Jallat, referring to the writings of Poincare that Valéry read before drafting the Introduction-that is, Les Géométries noneuclidiennes (1891), Le Continu mathématique (1893) and Sur la Nature du raisonnement mathématique (1894)—and identifying the points of correspondence between Poincaré and Valéry's text, finds in Valéry's reading of Poincaré the theoretic of invention, 'l'homme de la maniabilité opératoire', who reveals in mathematics 'activité productrice de figures et non plus comme de simples calculs'; see [16, pp. 238-239]. A summary comparison with the pages by Poincaré is also provided in [14], pp. 101-102].

${ }^{24} \mathrm{He}$ adds: L'intuition, par où s'opère la découverte, est une communion directe, sans intermédiaires possibles, de l'esprit et de la vérité. Il ne convient pas, il faut se garder, de troubler ce tête-àtête ". Ricordando che lo zio seguiva giorno dopo giorno i progressi dell'esplorazione del continente africano, definisce in conclusione il compito di Poincaré: "comme le grandes voyageurs de l'Afrique, remplir les espaces blancs de la carte du monde. See 'Lettre de M. Pierre Boutroux à M. Mittag-Leffler (1921)' in Euvres de Henri Poincaré, vol. XI, 1956, pp. 146-151 (quotes on pp. 147, 148 and 150).
}

the relationships between morals and science, lucidly set forth in the 1910 essay entitled La morale et la science (included in Dernières Pensées). Here he addresses the problem of the possibility of deriving ethical propositions from cognitive propositions, today known as 'Hume's law', after by the expression introduced by Richard Hare in 1952. According to Hume's law, it is impossible to pass from 'is' to 'ought', from scientific laws to moral behaviours. Poincaré highlights the impossibility of founding moral judgements on the laws of science, above all because of 'linguistic' reasons: the assertions of science are expressed in the indicative case, while those of morals are expressed in the imperative, and it is impossible to deduce imperative conclusions from premises expressed in the indicative. In so doing, he shows himself to be 'unwittingly' applying 'Hume's law' for the first time, and a great number of years before Hare's formulation of it, which the analytical ethics of the twentieth century had proved in a way that was logically incontrovertible. Hence, for Poincaré, it is possible to speak of a science of morals only in the sense of a description, comparison and explanation of the moral customs of men, which is limited to studying their ethical behaviours and their origins.

Also rather interesting are the reflections on the new concept of matter that arose from microphysics, which seeks to mitigate the din made by those who professed the 'end of matter' and to reconsider the concept of 'ether', so controversial at the time, in a linguistic and constructive way. In the 1906 essay La fin de la matière, reprinted as Chapter XIV in the 1907 edition of La science et l'hypothèse, Poincaré described the results furnished by the studies of the electron, which had not yet been brought together into the quantum theory of the atom proposed by Niels Bohr, to raise the image of a matter that 'moving ... doesn't remain identical with itself', immediately adding, however, in conclusion, that it would be premature to arrive at definitive conclusions. Writing successively of the relationships between matter and ether (the essay is included in Dernières Pensées), Poincaré remarks how much interest has grown in atomic theories, recalling Perrin's research on the atom, the studies of radioactivity, the investigations of the electron (a term attributed at the time to the various microphysical particles not yet subdivided and classified as protons, photons, etc.), and the new quantum theories. His discomfiture in the face of the 'old theories' is evident, as these do not hold up against the onslaught of the new, and contradictory, experiments of microphysics, leading Poincaré once again to avoid drawing any conclusions, recognising that 'we can only admit these difficulties without resolving them' [29, p. 101]. It is possible to identify in that discomfiture the roots of the search for a scientific atomism that would do away with the 'metaphysical' tradition of materialistic atomism, a search that—as Didier Gil has remarked—would become concrete 
only in Gaston Bachelard conception of 'rational materialism'. 25

But the most philosophically relevant reflection on this is found in the essay 'Les conceptions nouvelles de la matière', fruit of the lectures entitled 'Conferences de Foie et Vie' given in March 1912 and included posthumously in the collective volume Le materialisme actuel, which had a spiritual orientation [26]. After having upheld the intrinsic deterministic aspect of science, Poincaré goes into the presence of materialism in physical theories, recognising that in the history of science there is a recurring oscillation between atomism and continuism, mechanism and dynamism. Further, adds Poincare, it is undeniable that atomism has become stronger: from the kinetic theory of gases to the microphysical experiments of Perrin, the ground has been laid for a direct vision of atoms: il n'y a pas à dire, nous voyons les atomes [26, p. 60]. But at the very moment in which the material reality of atoms appeared to be beyond discussion, there in front of the researcher appeared an entire new world waiting to be discovered, that of microphysics, constituted of subatomic elements. Radioactivity, the experiments on electrons, gave the start to new research which, on one hand, seemed to confirm atomism (electrons are genuine 'atoms of electricity'), but on the other disproved it, casting doubt on the existence of a physical attribute that was fundamental to matter, mass: a matter that dissolves in radioactive isotopes, a matter without mass, which is what the electron appeared to be at the time, ceased to be 'material' in the classical meaning of the term. But now there appeared the Max Planck's quantum theory, which seemed to destroy definitively any continuous vision of nature. Nevertheless, Poincaré concluded, the struggle between atomism and continuism goes forward, although at levels that are increasing refined, carrying with it the development of physics and of science. ${ }^{26}$ On this occasion as on many others,

\footnotetext{
25 See [11], pp. 269-310]. Poincaré is mentioned on pp. 271, 292 and 306-307. Gil concludes: 'Lorsque, il a presque cent ans, Henri Poincaré affirmait que "parmi les théories physiques, il y en a qui sentent particulièrement le matérialisme", il se faisait l'écho d'une idée reçue par laquelle, depuis le début du XIX ${ }^{e}$ siècle, matérialisme et science étaient conjointement l'objet de soupçons ou d'accusations, et toute l'histoire de leur rapport recouverte d'un curieux contresens', a dual absurdity: 'la science ne saurait donc se définir par le matérialisme and la science n'est pas davantage la raison d'être du matérialisme', an absurdity unravelled-according to Gil—by Bachelard's 'rational materialism'.

${ }^{26}$ Poincaré concludes: '... nous ne sommes pas près de voir finir la lutte entre les deux façons de penser, celle des atomistes, qui croient à l'existence d'éléments ultimes, dont les combinaisons en nombre fini, mais très grande, suffiraient pour expliquer les aspects variés de l'univers, celle des partisans du continue et de l'infini. Cette lutte durera tant qu'on fera de la Science, tant que l'humanité pensera, parce qu'elle est due à l'opposition de deux besoins inconciliables de l'esprit humain, donc cet esprit ne saurait se dépouiller sans cesser d'être; celui de comprendre et nous ne pouvons comprendre que le fini, et celui de voir, et nous ne pouvons voir que l'étendue qui est infinie', [26], p. 67.
}

Poincaré's intellectual honesty prevents him from taking a position against 'materialism', as the organisers of the lecture on faith and life had hoped that he would.

It might be said, in conclusion, that the epistemological and philosophical thinking of Poincaré can be collocated at the limits of modernity, at the threshold of twentieth-century epistemology, suspended 'in the mists of the entre deux siècles' [1, p. XLII]. While his investigations of complex dynamic systems and his reflections on 'deterministic chaos' have grown increasingly important, today his intuitive theory of mathematics is treated with ambivalence, but it cannot be denied that his general vision of science, oriented by the genuine aim to seek the truth, takes into account a need still keenly felt today to understand the value of science per se. Poincaré was the last modern scientists, or as J. Vuillemin called him, the 'last great universal scientist', but perhaps he was at the same time the first contemporary epistemologist: as an epistemologist and as a philosopher he showed himelf to be a careful interpreter of his own times, ever open to the new in all areas of physics and mathematics, but also capable of listening to and discussing frankly the languages and theories of his fellow philosophers.

Translated from the Italian by Kim Williams

\section{References}

1. Bartocci, C.:Equazioni e orbite celesti: gli albori della dinamica topologica. In: C. Bartocci (ed.) H. Poincaré, Geometria e caso. Scritti di matematica e di fisica. Bollati Boringhieri, Torino (1995)

2. Boutroux, P.: L'œuvre philosophique d'Henri Poincaré. Revue de Métaphysique et de Morale XXI, 205-259 (1913)

3. Darrigol, O.:Diversité et harmonie de la physique mathématique dans les préfaces de Henri Poincaré. In: Pont J.-Cl., Freland, L., Padovani T., Slavinskaia L., (eds.) Pour comprendre le XIX ${ }^{\mathrm{e}}$. Histoire et philosophie des sciences à la fin du siècle. Olschki, Florence (2007)

4. De Broglie, M.:Henri Poincaré et la Philosophie. In: CEuvres de Henri Poincaré, vol. XI (Le livre du centenaire de la naissance de Henri Poincaré 1854-1954), pp. 71-77. Gauthier-Villars, Paris (1956)

5. Einstein, A.: Come io vedo il mondo. Newton-Compton, Rome (1975)

6. Enriques, F.:Problemi della scienza, Bologna, Zanichelli (1906). French trans. in two vols.: Les problèmes de la science et la logique, J. Dubois, trans., Paris, Alcan (1909) and Les concepts fondamentaux de la science. Leur signification réelle et leur acquisition psychologique, L. Rougier, trans. Flammarion, Paris, (1913)

7. Frank, Philipp: Modern science its philosophy. Harvard University Press, Cambridge (1949)

8. Freudenthal, H.:Poincaré et les fonctionnes automorphes. In: H. Poincaré (ed.) Oeuvres de Henri Poincaré, vol. XI, pp. 212-219. Académie des sciences, Paris (1916-1954)

9. Gargani, A.: Introduzione a Wittgenstein, 5th edn. Laterza, Roma-Bari (1993) (1st ed., 1973) 
10. Gil, D.:Autour de Bachelard. Esprit et matière, un siècle français de philosophie des sciences (1867-1962), 10. Matérialisme et science selon Bachelard. Encre Marine, Paris (2010)

11. Giedymin, J.: Science and convention. Essays on Henri Poincaré's philosophy of science and the conventionalist tradition. Pergamon Press, Oxford (1982)

12. Grünbaum, A.: Philosophical problems of space and time. Alfred A Knopf, New York (1963)

13. Hahn, H., Neurath, O., Carnap, R.: Wissenschafliche Weltauffassung: Der Wiener Kreis (1929). Italian trans., La concezione scientifica del mondo. Il Circolo di Vienna, S. Tugnoli Pattaro, trans., Rome-Bari, Laterza (1979); English trans. 'The Scientific Conception of the World: The Vienna Circle'. In: Neurath, M., Cohen, R. (eds.) O. Neurath, Empiricism and Sociology, pp. 299-318. Reidel, Dordrecht (1973)

14. Haller, R.:Il primo Circolo di Vienna. In: Gargani, A. (ed.) Il Circolo di Vienna ... tra la scoperta del senso e la scoperta della verità. Longo, Ravenna (1984)

15. Hainaut, J.:Trois veines dans l'arabesque du dess(e)in valéryen. In: Vogel, Ch. (ed.) Valéry et Léonard: le drame d'une rencontre. Genèse de l'Introduction à la méthode de Léonard de Vinci. Peter Lang, Frankfurt am Main (2007)

16. Jallat, J.: Introduction aux figures valéryennes (Imaginaire et théorie). Pacini, Pisa (1982)

17. Lalande, A.: Vocabulaire technique et critique de la philosophie, 13th edn. P.U.F, Paris (1980). (1st ed. 1902-23)

18. Miller, A.I.: Einstein, Picasso: space, time and the beauty that causes Havoc. Perseus Books, New York (2001)

19. Mooij, J.J.A.: La philosophie des mathématiques de Henri Poincaré. Gauthier-Villars/E. Nauwelaerts, Paris/Louvain (1966)

20. Neurath, O.: Le développement du Cercle de Vienne, et l'avenir de l'empirisme logique (1935). Italian trans., Il Circolo di Vienna e l'avvenire dell'empirismo logico, A. Zucconi, trans. (Rome: Armando, 1977)

21. Pais, A.: Subtle is the lord: the science and the life of Albert Einstein. Oxford University Press, Oxford (1982)

22. Poincaré, H.: 'Sur Les Hypothèses fondamentales de la Géométrie'. Bulletin de la Société Mathématique de France, XV, pp. 203-216 (1886-1887)

23. Poincaré, H.: L'espace et la géométrie. Revue de Métaphysique et de Morale III, 631-646 (1894)

24. Poincaré, La Science et l'Hypothèse, Paris, Flammarion (1902). English trans. Science and Hypothesis. In: The Foundations of Science.The Science Press, New York (1913) (this book contains translations of La Science et L'Hypothèse, La valeur de la science and Science et méthode)

25. Poincaré, H.: Sur un théorème de géométrie. Rendiconti del Circolo Matematico di Palermo 33, 375-407 (1912)

26. Poincaré, H.: 'Les conceptions nouvelles de la matière'. In: Bergson, Poincaré, et al. (eds.) Le matérialisme actuel. Flammarion, Paris (1913)

27. Poincaré, H.: Science et Méthode, Paris, Flammirion (1908). English trans. Science and Method. In: Poincaré, H. (ed.) The Foundations of Science. The Science Press, New York (1913)
28. Poincaré, H.: The evolution of laws, in mathematics and science last essays. Dover, New York (1963)

29. Poincaré, H.: 'The relations between matter and ether', in mathematics and science last essays. Dover, New York (1963)

30. Poincaré, H.: La valeur de la science, Paris, Flammarion (1905). Italian trans. Il valore della scienza, G. Polizzi, ed., Florence, La Nuova Italia (1994); English trans. 'The Value of Science' in The Foundations of Science, The Science Press, New York (1913)

31. Polizzi, G.: Poincaré nei Problemi della scienza: un incontro "geometrico". In: Bussotti, P. (ed.) Federigo Enriques e la cultura europea. Agorà Publishing, Lugano (2008)

32. Reichenbach, H.: The rise of scientific Philosophy. University of California Press, Berkeley and Los Angeles (1951)

33. Rougier, L.: La philosophie géométrique de Henri Poincaré. Alcan, Paris (1920)

34. Sanzo, U.: Poincaré e i filosofi. Milella, Lecce (2000)

35. Schlick, M.: Are Natural Laws Conventions? (1935). In: Schlick, M. (ed.) Philosophical Papers. Reidel, Dordrecht (1979)

36. Valéry, P.: Premières notes et esquisses de plans. In: Vogel, Ch. (ed.) Valéry et Léonard: le drame d'une rencontre. Genèse de l'Introduction à la méthode de Léonard de Vinci. Peter Lang, Frankfurt am Main (2007)

\section{Author Biography}

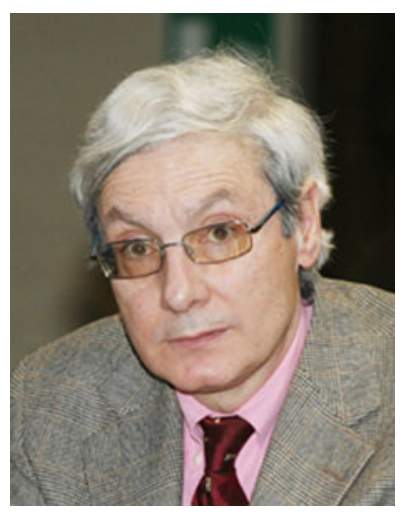

Gaspare Polizzi has taught history of philosophy at the IUL (the Italian University online) in Florence, and history of science and technology at the University of Florence. He is president of the Florence Chapter of the Società Filosofica Italiana. His principal research interests include the history of modern and contemporary philosophical and scientific thought, in particular French philosophy and epistemology (H. Poincaré, G. Bachelard, M. Serres) and natural philosophy 1700-1800 (G. Leopardi). He is the editor of Il valore della scienza (Florence, 1994) the Italian edition H. Poincaré's La Valeur de la Science. His other books include: Leopardi e "le ragioni della verità" (Rome, 2003), Galileo in Leopardi (Florence, 2007), "...per le forze eterne della materia ». Natura e scienza in Giacomo Leopardi (Milan, 2008), Einstein e i filosofi (Milan, 2009). His most recent book is Giacomo Leopardi: la concezione dell'umano, tra utopia e disincanto (Milan, 2011). 